\title{
25 Research Soure \\ Effect of Health Belief Model on the Participation in Fobt Crc Screening Programme: Case/Control Study
}

Martín Menéndez Rodríguez ( $\square$ martinmenendezrodriguez@hotmail.com )

University of Santiago de Compostela

Natalia García-Morales

Complexo Hospitalario Universitario de Vigo Sergas

Teresa Seoane Pillado

University of A Coruña-INIBIC, A Coruña

Jorge Garau Ramírez

Primary Health Center Chile, Área Hospital Clínic-Malvarrosa

Alba Traver Salvador

Primary Health Center Morella, Área de Salud de Vinaróz

Yésica Hervás Jiménez

Primary Health Center Chile, Área Hospital Clínic-Malvarrosa

Noel Pin Vieito

Hospital Universitario de Ourense

Luis Menéndez Rodríguez

Hospital Universitario de A Coruña, A Coruña

Joaquín Cubiella

Hospital Universitario de Ourense

\section{Research Article}

Keywords: Colorectal Neoplasms, Mass Screening, Mortality, Health Belief Model, Primary Health Care

Posted Date: November 8th, 2021

DOl: https://doi.org/10.21203/rs.3.rs-1005387/v1

License: (c) (i) This work is licensed under a Creative Commons Attribution 4.0 International License.

Read Full License 


\section{Abstract}

\section{Background}

Colorectal cancer is the second cancer-related cause of death in the world. Tumor stage at diagnosis is the principal prognosis factor of survival. However, the participation in the program is around $50 \%$. The aim of the study was to identify the benefits and barriers perceived by the population when participating in a colorectal cancer screening program with faecal occult blood test.

\section{Methods}

We carried out a cases-controls study with 408 participants. We analyzed epidemiological and social variables associated with lifestyle and behavioral factors based in the Health Belief Model. We conducted a descriptive analysis, and identified variables associated to adherence by a logistic regression.

\section{$\underline{\text { Results }}$}

Variables independently associated with the participation in a colorectal cancer screening program were age (OR 1.06; 95\% Cl: 1.01-1.11), having a stable partner (OR 1.96; 95\% Cl: 1.20-3.18), the level of education (OR 1.59; $95 \% \mathrm{Cl}: 1.02-2.47)$ and two of the barriers to participate in the faecal occult blood test screening: "not to know how to do it" (OR=0.46; $95 \% \mathrm{Cl}: 0.23-0.93)$ and "to take the test is currently not a major problem" (OR=0.43; 95\% Cl: 0.24-0.78).

\section{$\underline{\text { Conclusion }}$}

The existing barriers for screening with faecal occult blood test are the best factor predicting. This is relevant when designing the intervention programs, as they should focus on reducing perceived barriers to increase the participation in colorectal cancer screening, thereby reducing colorectal cancer mortality.

\section{Background}

Colorectal cancer (CRC) is the second most common cause of cancer-related deaths in the world, accounting 935.173 deaths in 2020. The incidence of this neoplasm, irrespective of gender, is the third highest after breast and lung cancer, with an estimated 1.931 .590 new cases in 2020 (1).

Five-year relative survival rate for patients with CRC in Spain is just $57 \%$. Survival of CRC patients detected in a screening programme is higher than that of patients diagnosed for symptoms (2). The screening strategy for medium-risk population (individuals over the age of 50 without additional risk factors) is a biennial Faecal Occult Blood Test (FOBT), sigmoidoscopy every 3-5 years or colonoscopy every 10 years (3). Although the coverage of the screening programmes is nearly universal in our country, participation in such programmes is still below $50 \%$ and most CRCs are still being diagnosed outside of the screening programmes (4). 
There are three groups of factors associated with adherence: those related to the organization of the screening programme (5), those related to social factors (6) and those dependent on the views of the individual. For this latter factor, several theoretical models of human behaviour have been adopted in an attempt to understand the subjective elements of the individual influencing his/her participation in preventive activities programmes. Some of these theories are the Bandura's Social Cognitive Theory, the Prochaska and DiClemente the Transtheoretical Model, Ajzen's Theory of Planned Behaviour and the Health Belief Model (HBM); the latter model is the most widespread and thoroughly assessed in the bibliography (7).

HBM was described by Rosenstock in 1966 (8). He states that decision making in healthcare is a process divided into different stages. This Model describes several cognitive concepts which predict behaviour in preventive activities: perceived susceptibility (belief about the risk of developing a health problem), perceived severity (belief about how serious a condition and its possible consequences are), perceived benefits (belief about the effectiveness of the tests to reduce the risks), perceived barriers (beliefs about the material and psychological obstacles to performing the preventive tests) and cues to action (the stimulus needed to trigger a behaviour modification). In 1988 a new dimension inspired by Bandura's Theory and called self-efficacy (the person's confidence in his/her own abilities) was added to the Model. Further on, the notion of perceiving treatment becomes relevant in the management of chronic pathologies (9)(10) (Figure 1).

Three systematic reviews (7)(11) (12) and a meta-analysis (13) support the adequacy of HBM in public health. We have HBM-based questionnaires validated for CRC screening in different populations with applications in research and clinical practice. In this respect, Jacobs adapted for colorectal cancer screening the questionnaire initially developed by Champion for breast cancer. Based on HBM cognitive concepts, Rawls validated in the United States a specific questionnaire for every screening test: FOBT, sigmoidoscopy and colonoscopy (14). Rawl's questionnaire was validated in several countries and in different populations and it is the most common in the bibliography (15)(16)(17)(18). The limitations of $\mathrm{HBM}$ are caused by its sidelining of the economic and emotional factors influencing human behavior (19).

The aim of the study was to identify the benefits and barriers perceived by the population when participating in a CRC screening program with FOBT.

\section{Methods}

We designed a case-control study performed in three primary health centers in Valencia, Spain: Chile, Argentina and Serrería II. We performed a simple random sampling among individuals invited to participate in the colorectal cancer screening programme. Data were collected by previously trained researchers from March to September 2019. The individuals agreeing to participate in the study were scheduled for an in-person appointment on the invitation of the researchers. 
We included subjects invited to participate in the CRC screening programme of the Comunitat Valenciana, to which all individuals between the ages of 50 and 69 years without symptoms and not meeting any of the permanent exclusion criteria to participate in the CRC screening programmes were invited. Permanent exclusion criteria are a personal history of CRC, inflammatory bowel disease, colorectal polyposis, colorectal adenoma, colectomized patients, individuals suffering from severe comorbidity or with a family history of familial adenomatous polyposis or other hereditary polyposis syndromes, hereditary nonpoliposis colorectal cancer, two or more first-degree relatives with CRC or one first-degree relative with CRC diagnosed before age 60 .

Exclusion criteria for this study were:

1. Individuals that declined to participate in the study.

2. Individuals meeting any of the permanent exclusion criteria of the CRC screening programmes.

We defined the cases are those individuals who agreed to participate in any round of the CRC screening programme of the Clínico-Malvarrosa health area in Valencia and took the FOBT test. Results of the FOBT test were registered in the colorectal cancer screening section of the Abucasis electronic medical records programme. On the other hand, we defined controls as those individuals who did not provide the faeces sample needed to perform the FOBT after being invited via post to participate in the CRC screening programme. Consequently, their participation is not registered in the colorectal cancer screening section of the Abucasis electronic medical records programme.

Sample size was calculated on the basis of an expected prevalence of low social support of $30 \%(20)$ a confidence interval of $95 \%$ and a potency of $80 \%$. The necessary number of individuals is 342 for an odds ratio of 2 .

The variables analyzed were as follows:

1. Sociodemographic factors: a. Age: defined as the age in years of the patient on the date of the collection of data for the study. b. Gender: male or female. c. Civil status: defined under the Civil Register rules as single, widowed, married, separated/divorced, or unmarried couples. d. Level of education: illiterate population and population with primary education, secondary education degree / middle level vocational training or university degree / higher level vocational training were considered. e. Social class: professional qualification of the patient on the date of the interview shall be assessed by adapting the British classification of social class to the Spanish reality (21)

2. Factors associated to lifestyle: a. Smoking habit: smoker - non-smoker. We defined an active smoking habit in those individuals smoking more than one cigarette per day during the three months prior to their participation in the study were classed as smokers. b. Alcohol consumption. Measured in Basic Units per Week (BUW). c. Body mass index (BMI). Weight (in kilograms) and height (in metres) were recorded. BMI was subsequently calculated by dividing weight in kilograms by the square of the height in metres. $d$. Family history of CRC in first- and second-degree relatives. Data were obtained by asking a direct question (yes/no) to the individual in the course of the clinical 
interview. e. other neoplasms in first- and second-degree relatives of the patient. Data were obtained by asking a direct question (yes/no) to the individual in the course of the clinical interview. $\mathrm{f}$. Personal history of non-CRC neoplasms: Yes-No. These data were obtained from the active medical records of the patient in the Abucasis computer programme.

3. Behavioural factors based on the health belief model (HBM). HBM was assessed by using Rawl's questionnaire for colorectal cancer screening. This questionnaire assesses two HBM dimensions, perceived barriers and benefits. The 2010 version of the questionnaire consists of 12 items to explore the benefits and barriers to perform the Faecal Occult Blood Test screening and is assessed with a 4point Likert scale (Annex 1: Rawl's questionnaire). The questionnaire was adapted and validated by our team in Spanish population, with satisfactory results in terms of validity, reliability and reproducibility (18). The self-administered questionnaire takes about 10 minutes to complete.

\section{Descriptive analysis}

A descriptive analysis was performed. We summarized the categorical variables in terms of absolute frequency and percentages and the quantitative variables using the mean and the standard deviation, together with its $95 \%$ confidence intervals. All tests were performed under a bilateral approach. Values of $p<0.05$ were considered significant. A bivariate analysis was conducted with the Chi-square test or Fisher's exact test for qualitative variables and Student's T-test for quantitative variables. Functional form of the variables was previously specified with the Kolmogorov-Smirnov test; nonparametric MannWhitney $U$ test was used in the cases in which non-normality was observed. Variables associated to adhesion to the screening programme were identified using logistic regression. Variables with a value of $p<0.05$ in the bivariate analysis were included in the initial multivariate model, as were clinically relevant variables, such as gender. The final model was built using a stepwise approach and likelihood ratio tests were applied to compare the models. To encourage the description of results, the four options of the Likert-type scale of the Rawl's questionnaire were grouped in agreement/disagreement. Likewise, due to the small illiterate population and/or population with primary education present in the sample, the level of education was codified as non-university/university education. Statistical analysis was carried out using BM SPSS Statistics software for Windows, Version 22.0. Armonk, NY: IBM Corp, and Epidat 4.2 software (Consellería de Sanidade - Xunta de Galicia [Department of Health, Galician Regional Government], in cooperation with the Organización Panamericana de la Salud [Pan-American Health Organization], OPSOMS).

\section{Ethical considerations}

This study has been approved by the Comité Ético de Investigación de la Dirección General de Salud Pública y Centro Superior de Investigación en Salud Pública de Valencia (CEIDGSP-CSISP) [Research Ethics Committee of the General Directorate for Public Health and Higher Centre for Public Health Research of Valencia], under registration number 20190301/04. The project was developed in accordance with the Declaration of Helsinki, the International Guidelines for Ethical Review of Epidemiological Studies, the European and Spanish regulations on biomedical research and the European (General Data 
Protection Regulation 2016/679, GDPR 2016) and Spanish (Organic Law 3/2018, of 5 December, on the Protection of Personal Data and Guarantee of Digital Rights; LOPDP-2018) regulations on the protection of personal data. The researchers signed a confidentiality agreement and specific measures were also taken to maintain the integrity and security of the data and to prevent the access of third parties to any identified or identifiable personal data. No paper or report derived from the study shall use or contain identified or identifiable data or images.

\section{Results}

A total of 1,017 individuals were invited to participate in the study. As shown in figure 2, 358 individuals could not be contacted; 128 did not want to participate; 80 were unable to attend the interviews; and 43 did not meet the criteria for inclusion. 
Table 1

Description of subjects included in the study

\begin{tabular}{|c|c|c|c|c|c|}
\hline & \multirow[b]{2}{*}{ Total } & \multicolumn{4}{|c|}{$\begin{array}{l}\text { ADHERENCE TO COLORECTAL } \\
\text { CANCER SCREENING }\end{array}$} \\
\hline & & Cases & Controls & $P$ & $\begin{array}{l}\text { OR } \\
(95 \% \\
\mathrm{Cl})\end{array}$ \\
\hline Mean age; mean (sd) & $\begin{array}{l}59.29 \\
(5.24)\end{array}$ & $\begin{array}{l}60.19 \\
(4.88)\end{array}$ & $\begin{array}{l}58.57 \\
(5.31)\end{array}$ & 0.01 & $\begin{array}{l}1.07 \\
(1.02 \\
1.11)\end{array}$ \\
\hline Gender: being a woman; $\mathrm{n}(\%)$ & $\begin{array}{l}221 \\
(54.20)\end{array}$ & $\begin{array}{l}133 \\
(56.10)\end{array}$ & $\begin{array}{l}88 \\
(51.50)\end{array}$ & 0.35 & $\begin{array}{l}1.21 \\
(0.81- \\
1.79)\end{array}$ \\
\hline Alcohol abuse; n(\%) & $\begin{array}{l}23 \\
(5.70)\end{array}$ & $\begin{array}{l}11 \\
(4.70)\end{array}$ & $\begin{array}{l}12 \\
(7.10)\end{array}$ & 0.31 & $\begin{array}{l}0.65 \\
(0.28- \\
1.51)\end{array}$ \\
\hline Smokers; n(\%) & $\begin{array}{l}113 \\
(27.70)\end{array}$ & $\begin{array}{l}57 \\
(24.10)\end{array}$ & $\begin{array}{l}56 \\
(32.70)\end{array}$ & 0.05 & $\begin{array}{l}0.65 \\
(0.42 \\
1.01)\end{array}$ \\
\hline Body mass index; mean (sd) & $\begin{array}{l}26.03 \\
(4.25)\end{array}$ & $\begin{array}{l}26.01 \\
(4.42)\end{array}$ & $\begin{array}{l}26.03 \\
(4.15)\end{array}$ & 0.97 & $\begin{array}{l}1.00 \\
(0.96- \\
1.05)\end{array}$ \\
\hline Family history of colorectal cancer; $\mathrm{n}(\%)$ & $\begin{array}{l}82 \\
(20.10)\end{array}$ & $\begin{array}{l}54 \\
(22.80)\end{array}$ & $\begin{array}{l}28 \\
(16.40)\end{array}$ & 0.11 & $\begin{array}{l}1.51 \\
(0.91- \\
2.50)\end{array}$ \\
\hline Family history of other neoplasms; $n(\%)$ & $\begin{array}{l}227 \\
(55.60)\end{array}$ & $\begin{array}{l}137 \\
(57.80)\end{array}$ & $\begin{array}{l}90 \\
(52.60)\end{array}$ & 0.30 & $\begin{array}{l}1.23 \\
(0.83- \\
1.83)\end{array}$ \\
\hline Family history of other non-CRC neoplasms; n(\%) & $\begin{array}{l}45 \\
(11.00)\end{array}$ & $\begin{array}{l}30 \\
(12.70)\end{array}$ & $\begin{array}{l}15 \\
(8.80)\end{array}$ & 0.22 & $\begin{array}{l}1.51 \\
(0.78- \\
2.90)\end{array}$ \\
\hline Social class: unskilled workers; $\mathrm{n}(\%)$ & $\begin{array}{l}61 \\
(15.00)\end{array}$ & $\begin{array}{l}29 \\
(12.20)\end{array}$ & $\begin{array}{l}32 \\
(18.70)\end{array}$ & 0.07 & $\begin{array}{l}0.61 \\
(0.35 \\
1.05)\end{array}$ \\
\hline Civil status: married or living with a partner; $\mathrm{n}(\%)$ & $\begin{array}{l}294 \\
(72.10)\end{array}$ & $\begin{array}{l}186 \\
(78.50)\end{array}$ & $\begin{array}{l}108 \\
(60.20)\end{array}$ & 0.01 & $\begin{array}{l}2.13 \\
(1.37 \\
3.30)\end{array}$ \\
\hline $\begin{array}{l}\text { Level of education: percentage of individuals with } \\
\text { higher education; } \mathrm{n}(\%)\end{array}$ & $\begin{array}{l}240 \\
(58.80)\end{array}$ & $\begin{array}{l}150 \\
(63.30)\end{array}$ & $\begin{array}{l}90 \\
(52.60)\end{array}$ & 0.03 & $\begin{array}{l}1.55 \\
(1.04 \\
2.31)\end{array}$ \\
\hline
\end{tabular}

Mean age of the analyzed sample was $59.29 \pm 5.24$ years (CI 95\%: 58.96-59.62). Women accounted for $52.40 \%$ of the individuals in the sample (95\% Cl: $49.24-55.48) ; 72.30 \%$ were non-smokers ( $95 \% \mathrm{Cl}$ : 67.99 76.89); and 25.40\% were teetotalers (95\% Cl: 21.09-29.77). Mean Body Mass Index was $26.03 \pm 4.25$ $\mathrm{kg} / \mathrm{m} 2$. Individuals with a family history of CRC accounted for $20.10 \%$ (95\% Cl: $16.01-23.99) ; 55.60 \%$ had 
a family history of other neoplasms (95\% Cl: 50.68-0.54); and $11.00 \%$ had a personal history of non-CRC neoplasms (95\% Cl: 7.83-14.12). Individuals with higher education accounted for $58.90 \%$ of the sample, as opposed to $22.50 \%$ with a secondary education degree, $17.60 \%$ with primary education and $1 \%$ illiterate. The percentage of married individuals was $72.10 \%$. With regard to social class, $43.90 \%$ of the individuals in the sample were company directors or managers, $37.20 \%$ held mid-level positions, $10.30 \%$ were skilled workers and $15 \%$ were unskilled workers. Rawl's questionnaire was self-administered in $87.80 \%$ of the cases, as opposed to $12.20 \%$ of the cases in which it was directed. No statistically significant differences were found between cases and controls with regard to the two forms of completing the questionnaire.

A statistically significant association was detected between adhesion to CRC screening program and an older age $(60.19 \pm 4.88$ vs. $58.57 \pm 5.31$ years; $\mathrm{OR}=1.07,95 \% \mathrm{Cl}: 1.02-1.11)$, having a stable partner (78 $.50 \%$ vs. $60.20 \%$; OR=2.13, $95 \% \mathrm{Cl}: 1.37-3.30)$ and having a higher education $(63.30 \%$ vs. $52.60 \%$; $\mathrm{OR}=1.55,95 \% \mathrm{Cl} 1.04-2.31$ ). No differences were found between both groups with regard to family or personal history of cancer.

When conducting the bivariate analysis of each one of the questions in Rawl's questionnaire, no significant differences were found in the three items measuring the CRC screening benefits. On the contrary, there are statistically significant differences in some of the barriers, as the people who do not collect the FOBT samples refer most commonly as an obstacle to have no time to take the test $(\mathrm{OR}=0.38$, $95 \% \mathrm{Cl}: 0.20-0.71)$; not to know how to do it $(\mathrm{OR}=0.30,95 \% \mathrm{Cl}$ : $0.16-0.56)$; it is an unpleasant test (OR=0.51, 95\% Cl: $0.31-0.84)$; to have no intestinal symptoms or problems (OR=0.54, 95\% Cl: $0.35-0.84)$; it is currently not a major problem $(\mathrm{OR}=0.41,95 \% \mathrm{Cl}: 0.25-0.69)$. Finally, the price of the test is on the verge of significance (Table 2).

Table 2 Scores of Rawl's scale for screening of colorectal cancer with faecal occult blood test 


\begin{tabular}{|c|c|c|c|c|c|}
\hline \multirow{2}{*}{\multicolumn{2}{|c|}{$\begin{array}{l}\text { QUESTION: } \\
\text { ¿Do taking regular faecal occult blood tests...? }\end{array}$}} & \multirow{2}{*}{\multicolumn{2}{|c|}{$\begin{array}{l}\text { ADHERENCE TO } \\
\text { COLORECTAL CANCER } \\
\text { SCREENING }\end{array}$}} & \multirow[t]{3}{*}{$P$} & \multirow{3}{*}{$\begin{array}{l}\text { OR (IC } \\
95 \%)\end{array}$} \\
\hline & & & & & \\
\hline & & Yes $(n(\%))$ & No $(n(\%))$ & & \\
\hline \multirow[t]{2}{*}{ help early detection of colon cancer? } & Agree & $\begin{array}{l}227 \\
(97.00 \%)\end{array}$ & $\begin{array}{l}156 \\
(93.40 \%)\end{array}$ & \multirow[t]{2}{*}{0.09} & \multirow{2}{*}{$\begin{array}{l}2.29 \\
(0.87- \\
6.03)\end{array}$} \\
\hline & Disagree & $7(3.00 \%)$ & $\begin{array}{l}11 \\
(6.60 \%)\end{array}$ & & \\
\hline \multirow[t]{2}{*}{$\begin{array}{l}\text { help decrease the likelihood of dying from } \\
\text { colon cancer? }\end{array}$} & Agree & $\begin{array}{l}221 \\
(96.90 \%)\end{array}$ & $\begin{array}{l}150 \\
(94.30 \%)\end{array}$ & \multirow[t]{2}{*}{0.21} & \multirow{2}{*}{$\begin{array}{l}1.89 \\
(0.69- \\
5.20)\end{array}$} \\
\hline & Disagree & $7(3.10 \%)$ & $9(5.70 \%)$ & & \\
\hline \multirow[t]{2}{*}{$\begin{array}{l}\text { help not to worry so much about colon } \\
\text { cancer? }\end{array}$} & Agree & $\begin{array}{l}215 \\
(93.10 \%)\end{array}$ & $\begin{array}{l}144 \\
(90.60 \%)\end{array}$ & \multirow[t]{2}{*}{0.37} & \multirow{2}{*}{$\begin{array}{l}1.40 \\
(0.67- \\
2.92)\end{array}$} \\
\hline & Disagree & $\begin{array}{l}16 \\
(6.90 \%)\end{array}$ & $\begin{array}{l}15 \\
(9.40 \%)\end{array}$ & & \\
\hline \multirow[t]{2}{*}{ Is worried about finding some problem. } & Agree & $\begin{array}{l}43 \\
(18.30 \%\end{array}$ & $\begin{array}{l}39 \\
(23.50 \%)\end{array}$ & \multirow[t]{2}{*}{0.20} & \multirow{2}{*}{$\begin{array}{l}0.73 \\
(0.45- \\
1.19)\end{array}$} \\
\hline & Disagree & $\begin{array}{l}192 \\
(81.70 \%)\end{array}$ & $\begin{array}{l}127 \\
(76.50 \%)\end{array}$ & & \\
\hline \multirow[t]{2}{*}{ Is embarrassed to take the test } & Agree & $\begin{array}{l}12 \\
(5.10 \%)\end{array}$ & $\begin{array}{l}15 \\
(9.00 \%)\end{array}$ & \multirow[t]{2}{*}{0.12} & \multirow{2}{*}{$\begin{array}{l}0.52 \\
(0.25- \\
1.20)\end{array}$} \\
\hline & Disagree & $\begin{array}{l}223 \\
(94.90 \%)\end{array}$ & $\begin{array}{l}151 \\
(91.00 \%)\end{array}$ & & \\
\hline \multirow[t]{2}{*}{ Has no time to take the test } & Agree & $18(7.7)$ & $\begin{array}{l}30 \\
(18.00 \%)\end{array}$ & \multirow[t]{2}{*}{0.01} & \multirow{2}{*}{$\begin{array}{l}0.38 \\
(0.20- \\
0.71)\end{array}$} \\
\hline & Disagree & $\begin{array}{l}216 \\
(92.30)\end{array}$ & $\begin{array}{l}137 \\
(82.00 \%)\end{array}$ & & \\
\hline \multirow[t]{2}{*}{ Does not know how to do it } & Agree & $\begin{array}{l}16 \\
(6.80 \%)\end{array}$ & $\begin{array}{l}32(19.80 \\
\%)\end{array}$ & \multirow[t]{2}{*}{0.01} & \multirow{2}{*}{$\begin{array}{l}0.30 \\
(0.16- \\
0.56)\end{array}$} \\
\hline & Disagree & $\begin{array}{l}220 \\
(92.20 \%)\end{array}$ & $\begin{array}{l}130 \\
(80.20 \%)\end{array}$ & & \\
\hline \multirow[t]{2}{*}{ Taking a sample of faeces is unpleasant } & Agree & $\begin{array}{l}34 \\
(14.50 \%)\end{array}$ & $\begin{array}{l}42 \\
(25.00 \%)\end{array}$ & \multirow[t]{2}{*}{0.01} & \multirow{2}{*}{$\begin{array}{l}0.51 \\
(0.31- \\
0.84)\end{array}$} \\
\hline & Disagree & $\begin{array}{l}201 \\
(85.50 \%)\end{array}$ & $\begin{array}{l}126 \\
(75.00 \%)\end{array}$ & & \\
\hline \multirow[t]{2}{*}{ It is an expensive test } & Agree & $3(1.40 \%)$ & $7(5.00 \%)$ & \multirow[t]{2}{*}{0.05} & \multirow{2}{*}{$\begin{array}{l}0.28 \\
(0.07- \\
1.09)\end{array}$} \\
\hline & Disagree & $\begin{array}{l}208 \\
(98.60 \%)\end{array}$ & $\begin{array}{l}134 \\
(95.00 \%)\end{array}$ & & \\
\hline
\end{tabular}




\begin{tabular}{|c|c|c|c|c|c|}
\hline \multirow[t]{2}{*}{$\begin{array}{l}\text { Does not have intestinal symptoms or } \\
\text { problems }\end{array}$} & Agree & $\begin{array}{l}52 \\
(22.30 \%)\end{array}$ & $\begin{array}{l}58 \\
(34.70 \%)\end{array}$ & \multirow[t]{2}{*}{0.01} & \multirow{2}{*}{$\begin{array}{l}0.54 \\
(0.35- \\
0.84)\end{array}$} \\
\hline & Disagree & $\begin{array}{l}181 \\
(77.70 \%)\end{array}$ & $\begin{array}{l}109 \\
(65.30 \%)\end{array}$ & & \\
\hline \multirow[t]{2}{*}{ Does not have privacy to take it at home } & Agree & $6(2.60 \%)$ & $\begin{array}{l}10 \\
(6.00 \%)\end{array}$ & \multirow[t]{2}{*}{0.09} & \multirow{2}{*}{$\begin{array}{l}0.42 \\
(0.15- \\
1.17)\end{array}$} \\
\hline & Disagree & $\begin{array}{l}228 \\
(97.40 \%)\end{array}$ & $\begin{array}{l}158 \\
(94.00 \%)\end{array}$ & & \\
\hline \multirow[t]{2}{*}{ It is currently not a major problem } & Agree & $\begin{array}{l}31 \\
(13.20 \%)\end{array}$ & $\begin{array}{l}44 \\
(26.80 \%)\end{array}$ & \multirow[t]{2}{*}{0.01} & \multirow{2}{*}{$\begin{array}{l}0.41 \\
(0.25- \\
0.69)\end{array}$} \\
\hline & Disagree & $\begin{array}{l}204 \\
(86.80 \%)\end{array}$ & $\begin{array}{l}120 \\
(73.20 \%)\end{array}$ & & \\
\hline
\end{tabular}

The BENEFIT dimension corresponds to the first three questions of the questionnaire and the BARRIER dimension to questions 4 to 12. By conducting an overall summation analysis of each dimension, it is evident that there are statistically significant differences between those who do not participate in the FOBT screening and those who do with regard to benefits ( $4.34 \pm 1.63$ as opposed to $3.89 \pm 1.63 ; p<0.04$ ) and barriers ( $14.28 \pm 4.50$ as opposed to $12.50 \pm 4.39 ; p<0.001)$, to the effect that those who participate in the screening perceive less barriers and those who do not perceive more benefits.

The multivariate regression model included all the variables that showed significance in the bivariate analysis and those considered clinically relevant, such as gender, tobacco use, family history of CRC, family history of other neoplasms, personal history of other neoplasms and the level of education. In this sense, variables independently associated with the participation in a CRC screening program were age (OR 1.06; 95\% Cl: 1.01-1.11), having a stable partner (OR 1.96; 95\% Cl: 1.20-3.18), the level of education (OR 1.59; 95\% Cl: 1.02-2.47) and two of the barriers to participate in the FOBT screening: "not to know how to do it" (OR=0.46, 95\% Cl: $0.23-0.93)$ and "to take the test is currently not a major problem" (OR=0.43, 95\% Cl: 0.24-0.78) (Table 3).

Table 3 Logistic regression for adherence to the programme of colorectal screening with faecal occult blood test. Dependent variable = case (participates in the screening) 


\begin{tabular}{|c|c|c|c|c|}
\hline & & \multirow[t]{2}{*}{ OR } & \multicolumn{2}{|c|}{ 95\% C.I. } \\
\hline & & & Upper & Lower \\
\hline \multirow[t]{2}{*}{ Gender } & Male & 1 & - & \\
\hline & Female & 1.22 & 0.78 & 1.89 \\
\hline \multirow[t]{2}{*}{ Age } & Current age & 1 & - & \\
\hline & For every completed year & 1.06 & 1.01 & 1.11 \\
\hline \multirow[t]{2}{*}{ With partner } & No & 1 & - & \\
\hline & Yes & 1.96 & 1.20 & 3.18 \\
\hline \multirow[t]{2}{*}{ Has no time to take the test } & Disagree & 1 & - & \\
\hline & Agree & 0.56 & 0.27 & 1.15 \\
\hline \multirow[t]{2}{*}{ Does not know how to do it } & Disagree & 1 & - & \\
\hline & Agree & 0.46 & 0.23 & 0.93 \\
\hline \multirow[t]{2}{*}{$\mathrm{CRC}$ is currently not a major problem } & Disagree & 1 & - & \\
\hline & Agree & 0.43 & 0.24 & 0.78 \\
\hline \multirow[t]{2}{*}{ Family history of CRC } & No & 1 & - & \\
\hline & Yes & 1.61 & 0.92 & 2.82 \\
\hline \multirow[t]{2}{*}{ Level of education } & Non-University & 1 & - & \\
\hline & University & 1.59 & 1.02 & 2.47 \\
\hline
\end{tabular}

\section{Discussion}

Our study found that the theoretical HBM model is consistent with CRC screening in the Spanish population. The perceived barriers stated by individuals with regard to the collection of FOBT samples appear as the most powerful cognitive concept of the Model, unlike the benefits of the screening. This has to be taken into account when planning educational interventions in the population.

Mean age of participants was around 60 years, in line with the age of similar studies, as it is the usual age range for medium-risk CRC screening (22)(23). We have found that older patients participate more in CRC screening (OR: 1.06). This coincides with other papers which also report a similar magnitude of the effect (24)(25)(26)(7). But it disagrees with other studies which do not find a correlation with age (16)(27) (28). 
We have not noted a difference between genders in our sample, as other authors have also noted (28)(16) (29). On the contrary, other studies (23)(7) note that women participate less than men in CRC screening. A recent systematic review (6) (Mosquera 2020) in which the majority of studies were carried out in Western countries concluded that women participate more in the collection of FOBT samples and less in colonoscopy with regard to men; all these gender differences can be related to the conditions of gender equality in each country.

The percentage of married people (72.10\%) in our study is similar to that of other papers (14)(15). Married patients in our study had increased participation in the CRC screening (OR 2.13). This connection is also found in the majority of published papers and is consistent with people who have greater social support (30)(31)(27)(28). There are, however, other series that do not find this connection to the civil status (26)(32).

Population in our sample is of urban middle / upper class extraction, partly comparable with that in a Turkish study by Ozsoy (15), as opposed to the majority of the published papers, in which the population is usually of low income and lower socio-cultural level(22)(33)(34). As in our case, several studies link a lower level of education and a lower participation in the CRC screening (32)(31)(27); on the other hand, Leung 2016 (16) and Jeihooni 2017 (28) do not find differences associated with the level of education. The relationship between the level of knowledge of the person about CRC and their participation in the screening shows differing results according to several studies (35)(34)(24). Some authors include the income level of the patients, as it is relevant in countries where patients must pay for the screening test (22)(36)(23). We do not include that level, as the Spanish Health System covers the costs of FOBT tests and colonoscopies. Rosentrock already noted in 1966 that the HBM model would be mainly applicable to the middle classes (8). This circumstance still has implications when designing the educational intervention programmes which must be adapted to the different social classes to which they are addressed.

The majority of the studies on CRC screening based on HBM are conducted in Asian countries. Following the conceptual HBM framework, we have noted in our study that BENEFITS of CRC screening are not associated to higher participation in the programme, as also noted by the majority of the authors of the published studies (24)(31)(27)(26)(35)(16). Contrary to what might be expected, we also found that patients participating in the screening do not perceive more benefits. This association is also found by Rawl in the initial validation of the questionnaire (14) and by Leung in the Hong Kong study, where it is also noted that those not participating in the screening perceive more barriers and fears, but there were no differences in the benefits (16). Kivinienmi's systematic review (7) does not find a relationship with benefits perceived after the CRC screening in 13 out of 35 analyzed studies of faecal occult blood tests. One of the renowned authors of the HBM points out that a possible explanation for this fact is that Benefits would be more predictive to promote healthy lifestyles (non-smoking) than other preventive activities (10). Other authors have suggested as an explanation that people reduce their perception of severity after participating in the screening. All this would explain the apparent paradox of people with personal or family history of cancer not significantly increasing their participation in CRC screening 
programmes, as noted in our results and by other authors (31)(27)(32). However, other series do find a relationship between between a history of cancer and CRC screening (26)(29). HBM indicates that decision making in health and lifestyle is a process in different phases influenced by the social norm and group to which the individual belongs. Longitudinal surveys must be designed in order to clarify this negative association opposite to the direction of the HBM theoretical model.

Our results clearly reflect that the BARRIERS raised by the individual to take a FOBT are the factor best predicting participation in CRC screening programmes. This is consistent with the HBM postulates which state that perceiving barriers is the most powerful dimension of the Model (25)(30)(19)(37). Barriers may be different depending on the different social, cultural or ethnic groups. It is therefore advisable to study human behaviour in different populations (7).

Among the barriers raised by the patient to avoid taking a FOBT, we found that to have no time to take the test; not to know how to take it; being an unpleasant test; to have no symptoms or problems; and to be currently not a major problem are those reaching statistical significance in our study. These findings are also referred by Janz in the study conducted in the United States (31), as well as by Javadzade (38) and Jeihooni (28) in Iran. Other authors refer other statistically significant barriers in patients from Hong Kong and Iran such as fear of cancer or being ashamed about taking the test, which we did not find (24)(27).

Multivariate analysis maintains not to know how to take the test (OR 0.46) and to be currently not a major problem (OR 0.43) as statistically significant. This magnitude of the effect is similar to that found by other authors in the United States, Asia or Iran with a ranging from 0.37 to 0.42 (31)(24)(26)(34). Several authors point out the Oyster Shell Strategy as a cognitive mechanism explaining many barriers; it would involve not taking the FOBT to delay the adverse consequences of a diagnosis and the belief that taking more tests would increase the odds of contracting illnesses (24)(39)(40).

We must point out as limitations in our study that we have measured only two out of the seven HBM dimensions. This was partly due to the choice of a fast measuring instrument to adapt ourselves to the time available in the primary care centres. On the one hand, perceiving susceptibility is referenced as contributing to understand preventive habits, but carries less weight than benefits and barriers; on the other hand, there is a consensus in that perceiving severity is the dimension with the lowest significance ratios in the Model (25)(19)(13). The remaining HBM dimensions are less assessed and are most applicable to chronic illnesses (10).

We do not specifically measure one of the most important facilitators to participation, such as the physician's recommendation or the type of health insurance (30)(24)(26)(29)(38). Other factors dependent on the healthcare provider or racial factors that we did not quantify have been referenced (41) (42). Asian doctors in Australia were noted to perceive more barriers for their patients to take the FOBT than Caucasian doctors regardless of their training, and CRC screening is less commonly recommended to immigrant patients (43). We also have to take into account the untraceable population in our study as it could introduce a bias for losses, although we did not find any differences with regard to age and gender when that population was included. 
The educational interventions that proved to be most effective to increase the participation in CRC screening are focused on promoting personalized health advice, removing barriers, improving accessibility to the test (which includes providing tests outside working hours), community interventions based on health workers and dissemination of information by the media (44)(45)(32)(46). To this regard, our results support the implementation of interventions aimed at eliminating barriers and improving the accessibility of FOBT.

\section{Conclusions}

As a conclusion, we can say that the existing barriers for screening with FOBT are the factor best predicting participation in CRC screening programs. This is significant when designing the intervention programs, as they should focus on reducing perceived barriers and improving accessibility to the test to increase the participation in CRC screening, thereby reducing CRC mortality. Longitudinal studies in different populations are necessary to make further progress in the understanding of human behavior in preventive activities and select the most effective intervention measures.

\section{Abbreviations}

CRC: Colorectal cancer

FOBT: faecal occult blood test

HBM: Health Belief Model

BUW: Measured in Basic Units per Week

BMl: Body mass index

$\mathrm{PH}$ : personal history

IBD: inflammatory bowel disease

SD: standard deviation

\section{Declarations}

Funding: This work received funding from the Spanish Society of Family and Community Medicine semFYC- by being the winner of a grant for the completion of doctoral theses Isabel Fernández 2021.

Competing interests: The authors declare that they have no competing interests.

Availability of data and material: The datasets used and/or analysed during the current study are available from the corresponding author on reasonable request. 
Ethics approval: The study was conducted according to the guidelines of the Declaration of Helsinki, and approved by the Ethics Committee of the General Directorate for Public Health and Higher Centre for Public Health Research of Valencia (protocol code 20190301/04 and date of approval 01/03/2019)

Consent to participate: Written informed consent was obtained from all subjects involved in the study.

Consent for publication: Not applicable

Authors' contributions:

Conceptualization: Natalia Garcia, Joaquín Cubiella, Martín Menéndez, Luis Menéndez

Methodology: Joaquin Cubiella, Teresa Seoane, Martín Menéndez, Noel Pin

Formal analysis: Teresa Seoane, Joaquín Cubiella, Martín Menéndez

Investigation: Martín Menéndez, Natalia García, Luis Menéndez, Noel Pin, Yésica Hervás

Data curation: Yesica Hervás, Jorge Garau, Alba Traver, Martín Menéndez

Writing-original draft preparation: Martín Menéndez

Writing-review and editing: Martín Menéndez, Natalia García

Supervision: Joaquín Cubiella

Acknowledgement: To all my promotion colleagues, tutors, and especially my father for his unconditional support.

\section{References}

1. Global Cancer Observatory. Estimated age-standardized incidence rates (World) in 2020, worldwide, both sexes, all ages. 2020;2020.

2. Gutierrez-Stampa MA, Aguilar V, Sarasqueta C, Cubiella J, Portillo I, Bujanda L. Impact of the faecal immunochemical test on colorectal cancer survival. BMC Cancer 2020 Jul 1 [cited $2021 \mathrm{Feb}$ 5];으(1):616.

3. Cubiella J, Marzo-Castillejo M, Mascort-Roca JJ, Amador-Romero FJ, Bellas-Beceiro B, ClofentVilaplana J, et al. Clinical practice guideline. Diagnosis and prevention of colorectal cancer. 2018 Update. Gastroenterol Hepatol. 2018;41(9):585-96.

4. Gutierrez-Stampa MA, Aguilar V, Sarasqueta C, Cubiella J, Portillo I, Bujanda L. Colorectal Cancer Survival in 50- to 69-Year-Olds after Introducing the Faecal Immunochemical Test. Cancers (Basel) [Internet]. 2020 Aug 25 [cited 2021 Feb 5];12(9):2412. 
5. Toes-Zoutendijk E, Portillo I, Hoeck S, de Brabander I, Perrin P, Dubois C, et al. Participation in faecal immunochemical testing-based colorectal cancer screening programmes in the northwest of Europe. J Med Screen [lnternet]. 2019 Jun 23 [cited 2021 Feb 5];그(2)

6. Mosquera I, Mosquera I, Mosquera I, Mendizabal N, Martín U, Martín U, et al. Inequalities in participation in colorectal cancer screening programmes: A systematic review. Eur $\mathrm{J}$ Public Health [Internet]. 2020 Jun 1 [cited 2021 Feb 5];으(3):416-25

7. Kiviniemi MT, Bennett A, Zaiter M, Marshall JR. Individual-level factors in colorectal cancer screening: A review of the literature on the relation of individual-level health behavior constructs and screening behavior[Internet]. Vol. 20, Psycho-Oncology. Psychooncology; 2011 [cited 2021 Feb 5].p. 1023-33

8. Rosenstock IM. Why people use health services [Internet]. Vol. 83, Milbank Quarterly. Blackwell Publishing Inc.; 2005 [cited 2021 Feb 5].

9. Rosenstock IM, Stretcher VJ, Becker MH. Social Learning Theory and the Health Belief Model. Heal Educ Behav [Internet]. 1988 [cited 2021 Feb 5];15(2):175-83.

10. Champion VL, Skinner CS. Health Belief Model explained.pdf - CHAPTER 3 THE HEALTH BELIEF MODEL Victoria L Champion Celette Sugg Skinner KEY POINTS This chapter will \u428f $\backslash u 428 f$ lu428f | Course Hero [Internet]. HEALTH BEHAVIOR AND HEALTH EDUCATION Theory, Research, and Practice 4TH EDITION. 2008 [cited 2021 Feb 4]. p. 45-65.

11. Guessous I, Dash C, Lapin P, Doroshenk M, Smith RA, Klabunde CN. Colorectal cancer screening barriers and facilitators in older persons [Internet]. Vol. 50, Preventive Medicine. Prev Med; 2010 [cited 2021 Feb 5]. p. 3-10.

12. Chin $\mathrm{YH}, \mathrm{Ng} \mathrm{CH}$, Seah SHY, Jain SR, Law JH, Devi MK, et al. Evolving perspectives on stool testing for colorectal cancer: A qualitative systematic review. Eur J Cancer Prev. 2020;29(5):416-23.

13. Harrison JA, Mullen PD, Green LW. A meta-analysis of studies of the health belief model with adults. Health Educ Res. 1992;7(1):107-16.

14. Rawl S, Champion V, Menon U, Loehrer PJ, Vance GH, Skinner CS. Validation of scales to measure benefits of and barriers to colorectal cancer screening [Internet]. Vol. 19, Journal of Psychosocial Oncology. Taylor \& Francis Group; 2001 [cited 2020 Jun 27]. p. 47-63.

15. Ozsoy SA, Ardahan M, Özmen D. Reliability and validity of the colorectal cancer screening belief scale in Turkey. Cancer Nurs. 2007;30(2):139-45.

16. Leung DYP, Wong EML, Chan CWH. Determinants of participation in colorectal cancer screening among community-dwelling Chinese older people: Testing a comprehensive model using a descriptive correlational study. Eur J Oncol Nurs [Internet]. 2016;21(2016):17-23.

17. Tahmasebi R, Noroozi A, Dashdebi KG. Psychometric evaluation of the colorectal cancer screening belief scale based on health belief model's constructs for the fecal occult blood test. Asian Pacific $\mathrm{J}$ Cancer Prev. 2016;17(1):225-9.

18. Rodríguez MM, Ramírez JG, Salvador AT, Jiménez YH, Morales NG, Pillado TS, Vieito NP, Villaamil PV, Martínez AM CJ. Rawl's questionnaire spanish validation for colorectal cancer screening with faecal occult blood testing. Gastroenterol Hepatol [Internet]. 2021;20:S0210-5. 
19. Waine W; Lamorte MD. The Health Belief Model [Internet]. BOSTON UNIVERSITY OF PUBLIC HEALTH. 2019 [cited $2021 \mathrm{Feb} 6$ ]. modules/sb/behavioralchangetheories/behavioralchangetheories2.html

20. Menéndez-Villalva C, Gamarra-Mondelo MT, Alonso-Fachado A, Naveira-Castelo A, Montes-Martínez A. Social network, presence of cardiovascular events and mortality in hypertensive patients. J Hum Hypertens. 2015;29(7):417-23.

21. Domingo-Salvany A, Bacigalupe A, Carrasco JM, Espelt A, Ferrando J, Borrell C. Proposals for social class classification based on the Spanish NationalClassification of Occupations 2011 using neoWeberian and neo-Marxistapproaches. Gac Sanit. 2013;27(3):263-72.

22. Wang HL, Christy SM, Skinner CS, Champion VL, Springston JK, Perkins SM, et al. Predictors of stage of adoption for colorectal cancer screening among african american primary care patients. Cancer Nurs [Internet]. 2014 [cited 2021 Feb 5];37(4):241-51.

23. Green PM, Kelly BA. Colorectal cancer knowledge, perceptions, and behaviors in African Americans [Internet]. Vol. 27, Cancer Nursing. Cancer Nurs; 2004 [cited 2021 Feb 5]. p. 206-17.

24. Sung JJY, Choi SYP, Chan FKL, Ching JYL, Lau JTF, Griffiths S. Obstacles to colorectal cancer screening in Chinese: A study based on the Health Belief Model. Am J Gastroenterol. 2008;103(4):974-81.

25. Janz NK, Becker MH. The Health Belief Model: A Decade Later. Heal Educ Behav [Internet]. 1984 [cited 2021 Feb 5];11(1):1-47.

26. Cheng SY, Li MC, Chia SL, Huang KC, Chiu TY, Chan DC, et al. Factors affecting compliance with confirmatory colonoscopy after a positive fecal immunochemical test in a national colorectal screening program. Cancer. 2018;124(5):907-15.

27. Javadzade H, Hasanzade A, Reisi M, Sharifirad G, Mostafavi F, Shahnazi H. Factors associated with the fecal occult blood testing for colorectal cancer screening based on health belief model structures in moderate risk individuals, Isfahan, 2011. J Educ Health Promot. 2012;1(1):18.

28. Jeihooni AK, Kashfi SM, Shokri A, Kashfi SH, Karimi S. Investigating factors associated with FOBT screening for colorectal cancer based on the components of health belief model and social support. Asian Pacific J Cancer Prev. 2017;18(8):2163-9.

29. Wong RK, Wong ML, Chan YH, Feng Z, Wai CT, Yeoh KG. Gender differences in predictors of colorectal cancer screening uptake: A national cross sectional study based on the health belief model. BMC Public Health. 2013;13(1).

30. Menon U, Champion VL, Larkin GN, Zollinger TW, Gerde PM, Vernon SW. Beliefs associated with fecal occult blood test and colonoscopy use at a worksite colon cancer screening program. J Occup Environ Med [Internet]. 2003 Aug 1 [cited 2021 Feb 5];45(8):891-8.

31. Janz NK, Wren PA, Schottenfeld D, Guire KE. Colorectal cancer screening attitudes and behavior: A population-based study. Prev Med (Baltim). 2003;37(6):627-34.

32. Dashdebi KG, Noroozi A, Tahmasebi R. Factors predicting fecal occult blood testing among residents of Bushehr, Iran, based on the health belief model. Asian Pacific J Cancer Prev [Internet]. 2016 [cited 2021 Feb 6];17(S3):17-22. 
33. Lee SY, Lee EE. Cross-cultural validation of instruments measuring health beliefs about colorectal cancer screening among Korean Americans. J Korean Acad Nurs [Internet]. 2015 [cited 2021 Feb 5];45(1):129-38.

34. Taheri-Kharameh Z, Noorizadeh F, Sangy S, Zamanian H, Shouri-Bidgoli AR, Oveisi H. Factors associated with adherence to colorectal cancer screening among moderate risk individuals in Iran. Asian Pacific J Cancer Prev. 2016;16(18):8371-5.

35. Almadi M, Alghamdi F. The gap between knowledge and undergoing colorectal cancer screening using the Health Belief Model: A national survey. Saudi J Gastroenterol. 2019;25(1):27-39.

36. Leung DYP, Wong EML, Chan CWH. Psychometric properties of a chinese version of the colorectal cancer perceptions scale in a sample of older chinese people. Cancer Nurs. 2014;37(5):53-60.

37. Bidgoli ARS; Taheri AK;Asayesh H;Sharififard F. A Study of Knowledge, Attitude, and PracticeonColorectal Cancer Screening among Individuals Older than50 Years Based on Health Belief Model. Qom Univ Med Sci J [Internet]. 2015 [cited 2021 Feb 7];9(1):59-65.

38. Javadzade S, Reisi M, Mostafavi F, Tavassoli E, Sharifirad G, Heydarabadi A. Barriers related to fecal occult blood test for colorectal cancer screening in moderate risk individuals. J Educ Health Promot. 2014;3(1):120.

39. Huang X, Butow P, Meiser B, Goldstein D. Attitudes and information needs of Chinese migrant cancer patients and their relatives. Aust N Z J Med [Internet]. 1999 Apr 1 [cited 2021 Feb 7];29(2):207-13.

40. Foo ASC, Thia JJP, Ng ZP, Fong NP, Koh GCH. Colorectal cancer screening: The effectiveness of education on its barriers and acceptability. Asia-Pacific J Public Heal [Internet]. 2012 Jul [cited 2021 Feb 7];24(4):595-609.

41. Wolf MS, Rademaker A, Bennett CL, Ferreira MR, Dolan NC, Davis TC, et al. Development of a brief survey on colon cancer screening knowledge and attitudes among veterans. Prev Chronic Dis. 2005;2(2):1-10.

42. Thompson VLS, Harris J, Clark EM, Purnell J, Deshpande AD. Broadening the examination of sociocultural constructs relevant to African-American colorectal cancer screening. Psychol Heal Med [Internet]. 2015 Jan 2 [cited 2021 Feb 5];20(1):47-58.

43. Koo JH, You MY, Liu K, Athureliya MD, Tang CWY, Redmond DM, et al. Colorectal cancer screening practise is influenced by ethnicity of medical practitioner and patient. J Gastroenterol Hepatol. 2012;27(2):390-6.

44. Ueland AS, Hornung PA, Greenwald B. Colorectal cancer prevention and screening: A Health Belief Model-based research study to increase disease awareness. Gastroenterol Nurs [Internet]. 2006 [cited 2021 Feb 7];29(5):357-63.

45. Koo JH, Leong RWL, Ching J, Yeoh KG, Wu DC, Murdani A, et al. Knowledge of, attitudes toward, and barriers to participation of colorectal cancer screening tests in the Asia-Pacific region: A multicenter study. Gastrointest Endosc [Internet]. 2012 Jul [cited 2021 Feb 7];76(1):126-35.

46. Kelly K, Dolly B, Kennedy S, Atkins E, Coon M, King K, et al. Insure Me Cancer Free: An Intervention Utilizing a Dynamic Communication Model. Heal Behav Res. 2019;2(1). 
Figures

\section{Modifyng factors:}

Age, gender, ethnicity, personality, socioeconomics, knowledge

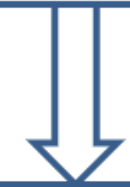

\section{Individual beliefs:}

Perceived susceptibility to and severity of disease $\rightarrow$ Perceived threat

Perceived benefits

Perceived barriers

Perceived self-efficacy

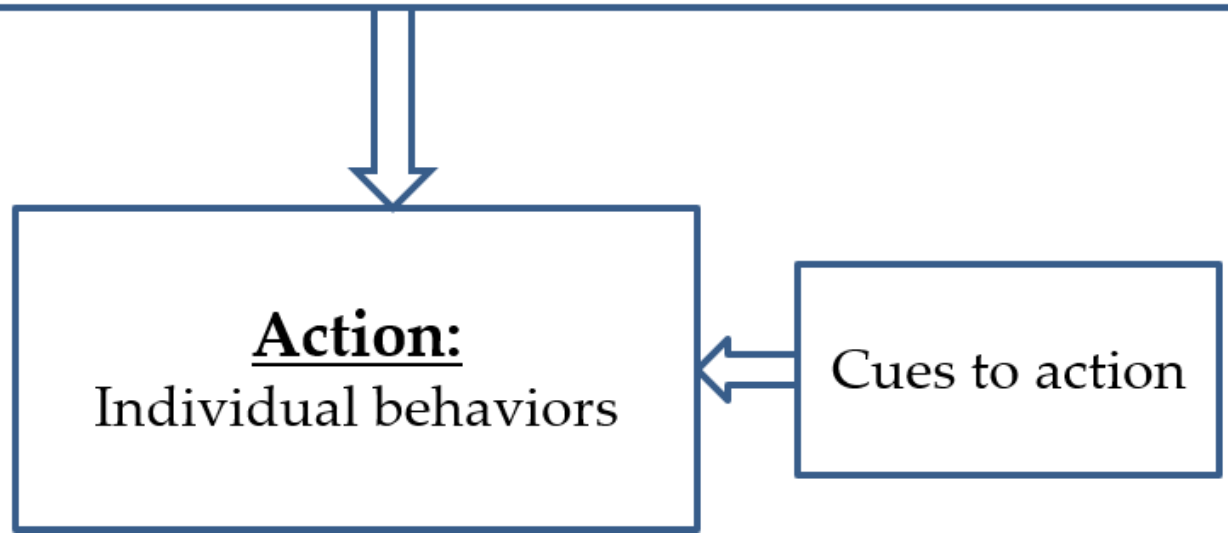

Figure 1

Conceptual framework of the Health Belief Model Components of the health belief model (Adapted of Champion \& Skinner 2008) 


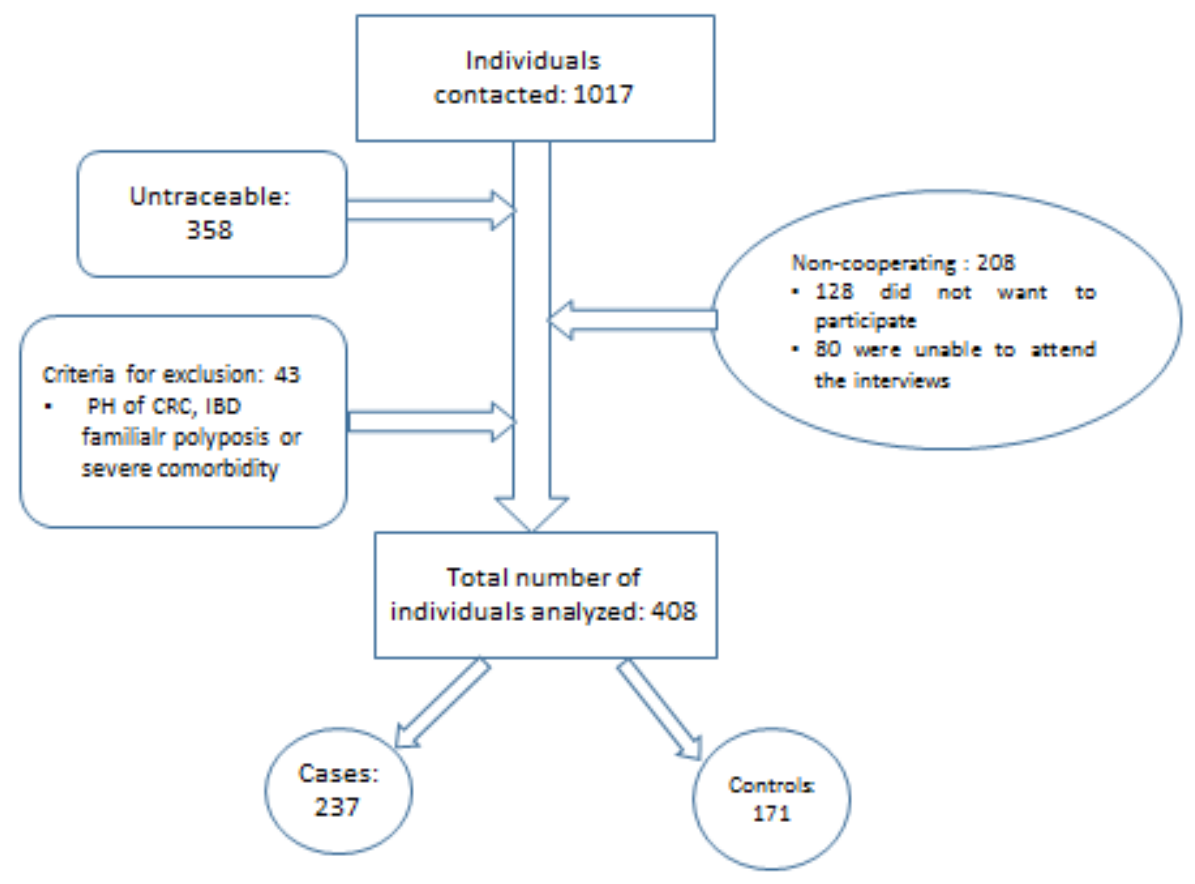

Figure 2

Flow chart Out of 408 individuals included, 237 participated in the screening programme (cases) and 171 did not participate (controls). No statistically significant differences were found between the individuals included/excluded with regard to age and gender. Main characteristics of the sample are shown in Table 1. 